\title{
Theoretical and experimental working life comparison for a helical gear under linear pitting failure
}

\author{
Muhammad Ali Khan ${ }^{1,}$, Andrew G Starr 2, b \\ ${ }^{1}$ Extreme loading and design research group, School of Mechanical, Aerospace and \\ Civil Engineering, University of Manchester M60 1QD, UK \\ ${ }^{2}$ Extreme loading and design research group, School of Mechanical, Aerospace and \\ Civil Engineering, University of Manchester M60 1QD, UK \\ amuhammad.khan-8@postgrad.manchester.ac.uk, \\ bandrew.g.starr@manchester.ac.uk
}

Keywords: Theoretical life, failure modes, linear pitting, BS-ISO standards.

\begin{abstract}
For machine components like gears and bearings, working life calculation is one of the complex issues to deal with. It is because the mechanics of their operation is depending on many parameters, like loading, friction and lubrication etc. Also the influence of these parameters on the component failure modes cannot be perfectly idealized. But in this regard, standards like AGMA (American gear manufactures association); ISO (International standard organization) and BS (British standards) are quite useful on the basis of which theoretical working life for machine components under a specific failure mode can be predicted. In this paper with linear pitting failure mode assumptions, theoretical working life calculation has been made for a helical gear. BS-ISO 6336-2 standard is used for the gear theoretical life calculations. Further more a wear debris analysis based experiment has been performed for the validation of theoretical calculation. A back to back gear testing rig has been used for the experimental validation. The experimental results show that the theoretical life calculation made on the basis of BS-ISO 6336-2 standards is fairly accurate.
\end{abstract}

\section{Introduction}

If limits of the surface durability of the meshing flanks are exceeded, particles will break out of the flanks, leaving pits. The extent to which such pits can be tolerated (in size and number) varies within wide limits, depending largely on the field of application. In some fields, extensive pitting can be accepted; in other fields any appreciable pitting is to be avoided [1].

So, criticality of gear pitting is depending upon the nature of application. To decide the unavoidable surface degradation limit of gear due to pitting, before its ultimate failure, is still a very vague concept to express. Researchers like P.Dempsey [2] had performed thorough predictive analysis for gear pitting failure. But her research is unable to decide a proper threshold for unavoidable surface degradation limit.

To develop a proper definition and threshold for gear unavoidable surface degradation, as a first step, below in this paper a theoretical and experimental effort is explained. In this effort, BS-ISO 6336-2 standard for pitting failure is used to estimate theoretical working life (i.e. gear life before avoidable surface degradation occurs) for a helical gear. In life estimation theoretical calculations, such values and assumptions 
for critical operating parameters like loading, speed, lubrication and gear physical dimensions have been selected that can lead a linear pitting failure on selected helical gear. To check the accuracy of this theoretical life estimation, a wear debris analysis based experimental effort was also performed by using a back to back gear failure testing rig. During comparison study it was found that standard based pitting failure theoretical life estimation may provide an aid to develop a proper definition for gear unavoidable surface degradation.

\section{Theoretical life calculation}

As per BS-ISO 6336-2, calculation of helical gear pitting failure is based on the contact stresses, ${ }^{\sigma_{\mathrm{H}}}$ at the pitch point of the meshing gears, or at the inner point of single pair tooth contact. ${ }^{\sigma_{H}}$ shall be less than its permissible ${ }^{\sigma_{H P}}$ for preventing failure and vice versa. Before detailing the calculation for ${ }^{\sigma_{H}}$, pre selected operational and gear physical dimension parameters are detailed below.

- Type of gears

- Helix angle

- Pressure angle

- Centre to centre distance

- Module of gear

- Number of teeth on gear

- Face width

- Tip diameter

- Pitch diameter (Also selecting as a reference diameter)

- Applied tangential loading (for pitting)

- Lubricant

- Gear Material hardened low carbon steel
Helical

$17.75^{\circ}$

$20^{\circ}$

$113 \mathrm{~mm}$

3

35

$15 \mathrm{~mm}$

$116.25 \mathrm{~mm}$

$110.25 \mathrm{~mm}$

$12104 \mathrm{~N}$

Mobile ATF 200

En32,Case

In case of helical gear ${ }^{\sigma_{H}}$ will be determined on pitch point of gear when overlapping ratio ' $\varepsilon_{\beta}$ ' of meshed gears is $\geq 1$. While when $\varepsilon_{\beta}$ is less than 1 , then $\sigma_{H}$ will be determined by linear interpolation between two limit value, i.e. ${ }^{\sigma_{H}}$ for spur gears and $\sigma_{\mathrm{H}}$ for helical gears with $\varepsilon_{\beta}=1$.

As per our selection of gear physical dimensions calculated value of $\varepsilon_{\beta}$ is 0.485 . So in further calculation we have used $\varepsilon_{\beta}=1$.

The formula of contact stress for the pinion gear is;

$$
\sigma_{H}=z_{B} \sigma_{H O} \sqrt{K_{A} K_{V} K_{H \beta} K_{H \alpha}} \leq \sigma_{H P}
$$

Where,

$$
\begin{array}{ll}
\mathrm{Z}_{\mathrm{B}} & =\text { pinion single pair tooth contact factor } \\
\sigma_{\mathrm{HO}} & =\text { nominal contact stress at the pitch point } \\
\mathrm{K}_{\mathrm{A}} & =\text { application factor (It takes into account the load increment } \\
& \text { due to externally influenced variations of input or output } \\
& \text { torque) }
\end{array}
$$



$\mathrm{K}_{\mathrm{V}} \quad=$ dynamic factor (It takes into account load increments due to internal dynamic effects)
$\mathrm{K}_{\mathrm{H} \beta} \quad$ = face load factor for contact stress (It takes into account uneven distribution of load over the face width, due to mesh misalignment caused by inaccuracies in manufacture, elastic deformations etc)
$\mathrm{K}_{\mathrm{H} \alpha} \quad=$ transverse load factor for contact stress (It takes into account uneven load distribution in the transverse direction resulting, for example, from pitch deviation)

As per formulation provided in BS-ISO 6336-2,

$\mathrm{Z}_{\mathrm{B}}$ (for spur gear) and $\mathrm{Z}_{\mathrm{B}}$ (for helical gear) $=1$

$\sigma_{\mathrm{HO}}($ for spur gear $)=1598.74 \mathrm{~N} / \mathrm{mm}^{2}, \sigma_{\mathrm{HO}}($ for helical gear $)=1482.189 \mathrm{~N} / \mathrm{mm}^{2}$

$\mathrm{K}_{\mathrm{A}}$ (As we have uniform loading, for spur as well as helical gear) $=1$

$\mathrm{K}_{\mathrm{V}}$ (for spur as well as helical gear) $=1.031$

$\mathrm{K}_{\mathrm{H} \beta}$ (for spur as well as helical gear) $=1.00294$

$\mathrm{K}_{\mathrm{H} \alpha}$ (for spur as well as helical gear) $=0.8826$

Therefore, ${ }^{\sigma_{\mathrm{H}}}$ for spur gear $=1527.3 \mathrm{~N} / \mathrm{mm}^{2}, \sigma_{\mathrm{H}}$ for helical gear $=1415.96 \mathrm{~N} / \mathrm{mm}^{2}$

By using a linear interpolation $\sigma_{\mathrm{H}} @ \varepsilon_{\beta}=0.485=1470 \mathrm{~N} / \mathrm{mm}^{2}$

Now for permissible contact stress ' $\sigma_{H P}$ ' the formula is: $\sigma_{H P}=\frac{\sigma_{H l i m} z_{N T} Z_{L} z_{V} z_{R} z_{W} Z_{X}}{S_{H \min }}$

Where,

$\begin{array}{ll}\sigma_{\mathrm{Hlim}} & =\text { Allowable stress number } \\ \mathrm{Z}_{\mathrm{NT}} & =\text { Life factor for contact stress } \\ \mathrm{Z}_{\mathrm{L}} & =\text { Lubrication factor } \\ \mathrm{Z}_{\mathrm{V}} & =\text { Velocity factor } \\ \mathrm{Z}_{\mathrm{R}} & =\text { Roughness factor } \\ \mathrm{Z}_{\mathrm{W}} & =\text { Work hardening factor } \\ \mathrm{Z}_{\mathrm{X}} & =\text { Size factor } \\ \mathrm{S}_{\mathrm{Hmin}} & =\text { Safety factor }\end{array}$

As per formulation provided in BS-ISO 6336-2,

$\sigma_{\text {Hlim }}=420 \mathrm{~N} / \mathrm{mm}^{2}$

$\mathrm{Z}_{\mathrm{NT}}$ (for spur/helical gear@ $\leq 10^{5}$ load cycles)=1.6

$\mathrm{Z}_{\mathrm{L}}=0.92$

$\mathrm{Z}_{\mathrm{V}}=0.975$

$\mathrm{Z}_{\mathrm{R}}=0.99$

$\mathrm{Z}_{\mathrm{W}}=1.211$

$\mathrm{Z}_{\mathrm{X}}=1$

$\mathrm{S}_{\mathrm{Hmin}}$ (from ESDU 88033 [3], consider as industrial application gear) $=1.1$

Therefore, $\sigma_{\mathrm{HP}}=795 \mathrm{~N} / \mathrm{mm}^{2}$

As $\sigma_{H P}<\sigma_{H}$, so the theoretical life of selected helical gear for limited pitting is less than $10^{5}$. By performing a very gross assumption, as $\sigma_{\mathrm{H}}=1.85 \sigma_{\mathrm{HP}}$, so start time of limited pitting will be $10^{5} / 1.85=9.01$ hours. 
Note: Also we have selected pinion and wheel gears of same physical dimensions. So the calculation and value of ${ }^{\sigma_{\mathrm{H}}}$ will be same for both of them.

\section{Experimental setup, observation and analysis for theoretical life verification}

As per the details given above, a pair of case hardened low carbon steel gears with a face width of $15 \mathrm{~mm}$ and having 35 teeth's was selected for gear pitting failure test. The gears were tested for 21 hours on a back to back gear rig as shown in figure 1 . In which after 12 hour operation visible micro pitting was identified. After every 3 hours visible inspection of gears was done and loaded gear teeth's images were captured by using micro imaging capable digital camera. After every one hour wear debris bottle sampling had been done at the sampling point that is provided in the gear rig oil piping before the filter as shown in figure 2. Magnetic plug wear debris sampling was also put under observation after every one hour. Two magnetic plugs at different positions in the tested gear box were used during the experiment. Due to handling problems hour 3 bottle and magnetic sample data could not be recorded.

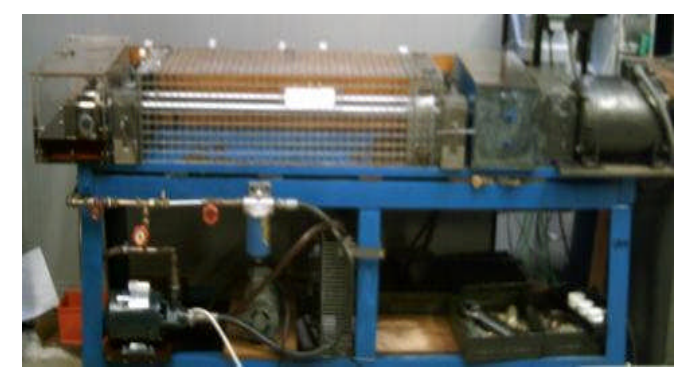

\section{Figure 1 Back to back gear testing rig}

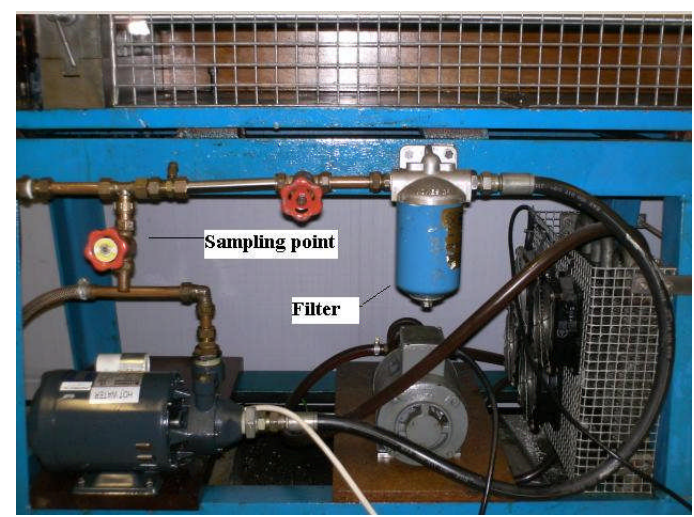

Figure 2 Sampling point and filter arrangement on Back to back gear testing rig

For wear debris quantitative measurement, as when collected in bottle and magnetic oil samples, Arti's Portable Oil Diagnostic System (PODS), as shown in figure 3, was used.

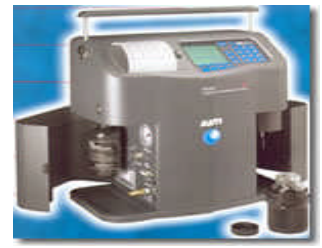

Figure 3 Arti's PODS 
Observations of quantitative wear debris measurement for both bottle and magnetic sampling were recorded. By using these observations pitting failure diagnostic trends are plotted as shown in below figure 4 and 5. For each sampling mode (i.e. bottle and magnetic) two diagnostics trends are shown in figures 4 and 5. One of them is plotted on real values and other one is plotted by using a 3-degree polynomial in order to perform pitting failure diagnostics. As from the literature knowledge [4] it is well known that in gear operating life cycle, we have three operating life zones. On the basis of debris quantity trends, all of them are can be easily marked on quantity vs. time curve, as marked on below figure 4 and figure 5. By the help of the available trends, rough estimation of gear life operating zones has been made as:

- Running in zone:

$0 \mathrm{hrs}-5.5 \mathrm{hrs}$

- Normal working zone:

$5.5 \mathrm{hrs}-9.8 \mathrm{hrs}$

- Failure zone :

$9.8 \mathrm{hrs}$ (pitting start time)

- Onwards

This rough estimation of gear operating life zones times are also verified by means of visual inspections and camera imaging as shown in figure 6.

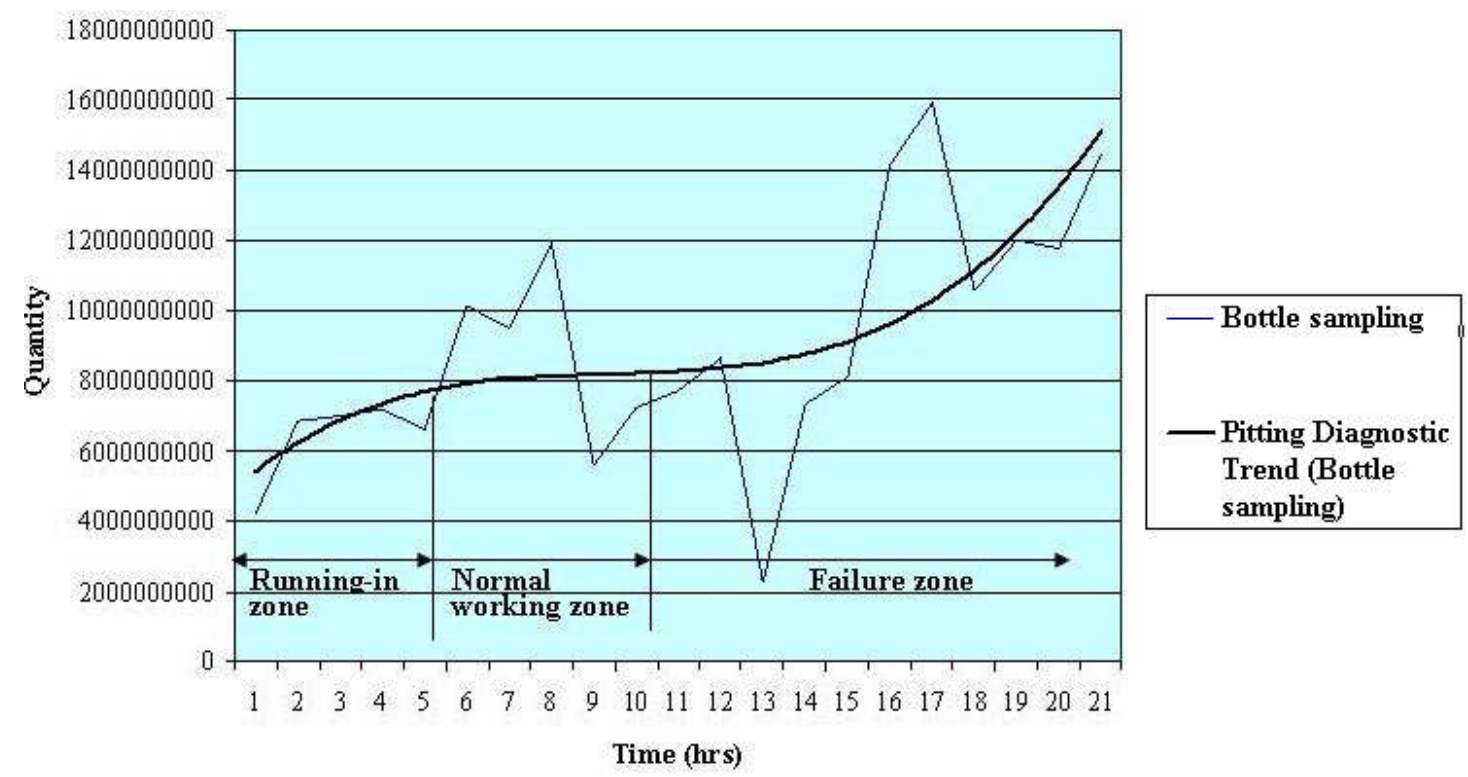

Figure 4. Pitting diagnostics trend from bottle sampling
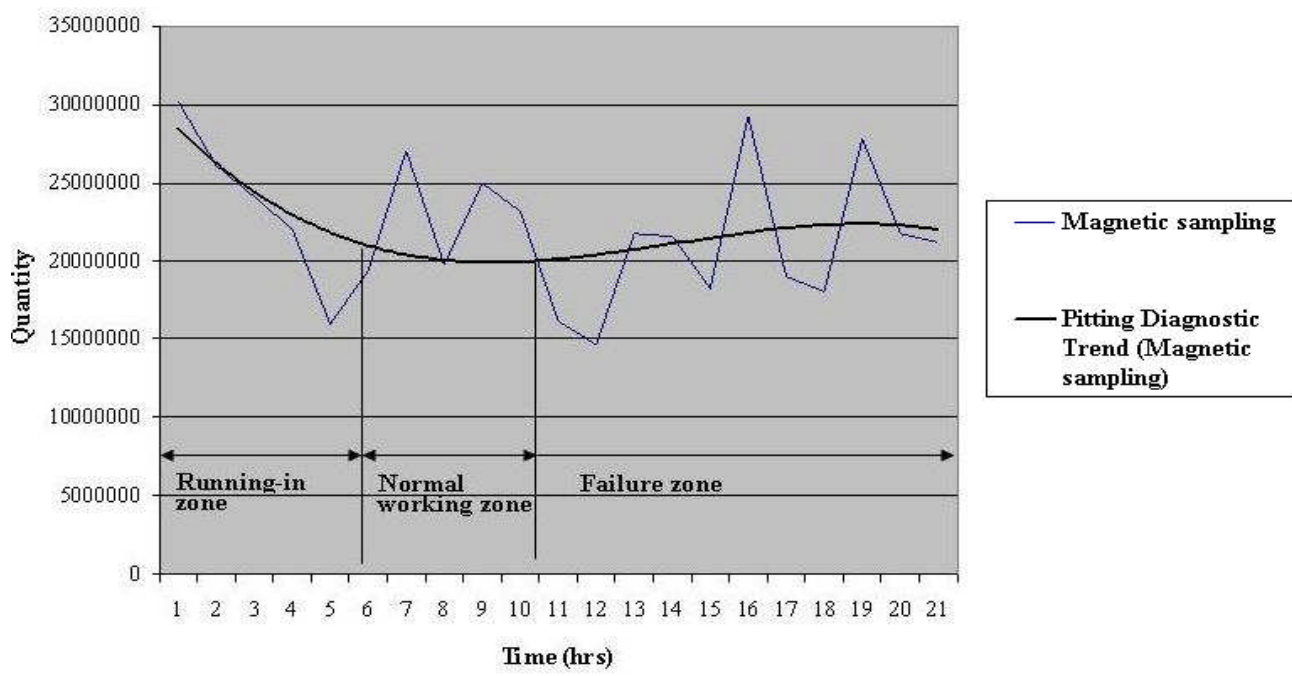

Figure 5. Pitting diagnostics trend from magnetic sampling 

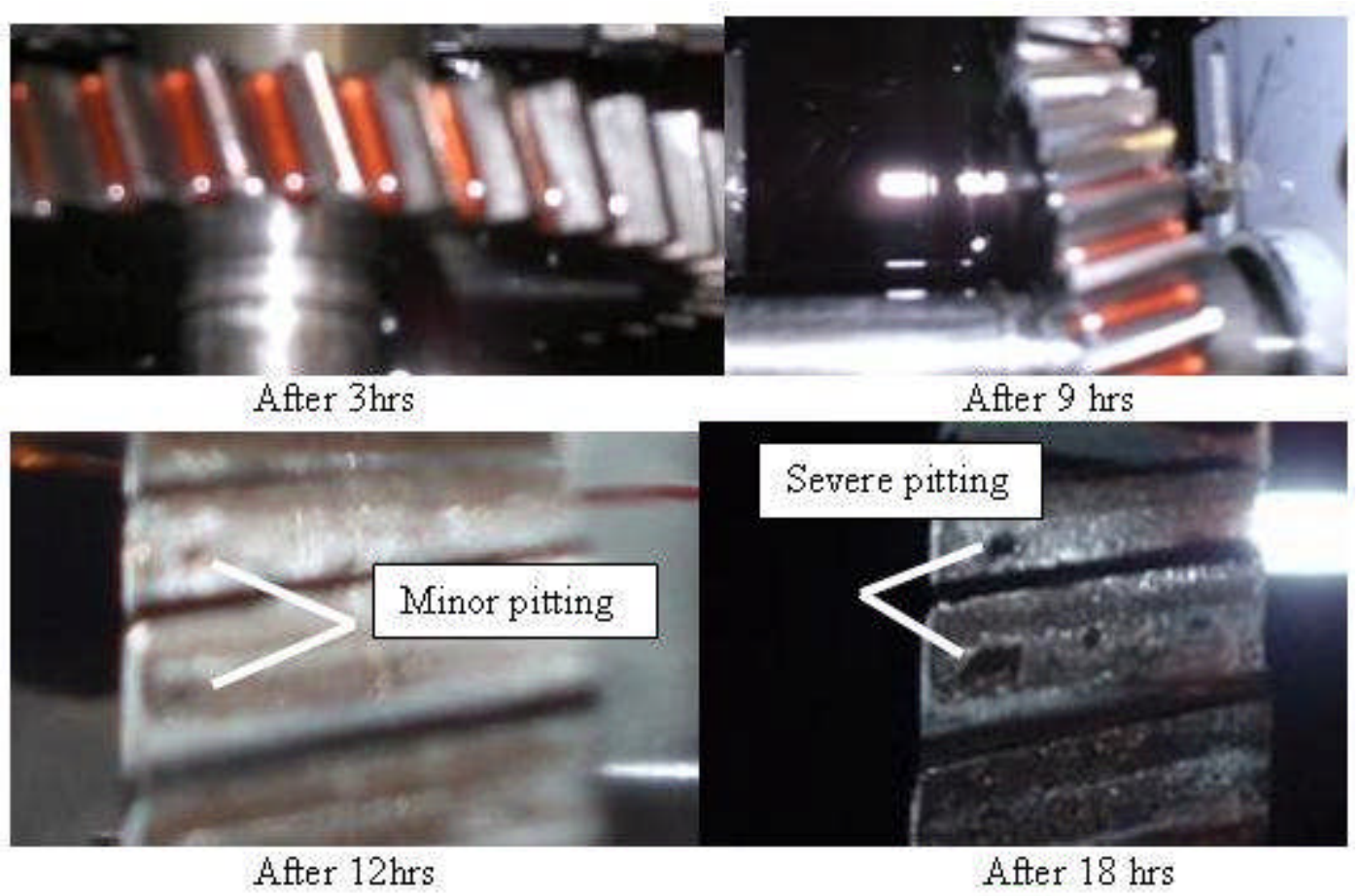

Figure 6. Gear images before and after failure

\section{Conclusion}

On the basis of BS-ISO 6336-2 standard the theoretical life for the selected helical gear when limited pitting is permissible is slightly above than 9 hours. While from performed experiment and diagnostics analysis it is clearly identified that pitting was started on the selected pair of helical gear between hour 9 and hour 10. This shows that theoretical formulations available in BS-ISO 6336-2 standard are reliable to calculate helical gear theoretical life. On the behalf of this fairly accurate approach for helical gear life estimation, research related to unavoidable surface degradation limit of helical gear due to pitting, before its ultimate failure, is in plan to perform in future.

\section{References}

[1] BS ISO Standard, Calculation of load capacity of spur and helical gears Calculation of surface durability (pitting), BS ISO 6336-2: 1996

[2] P.J.Dempsey: Integrating Oil Debris and Vibration measurement for Intelligent machine health monitoring, Report- NASA/TM-2003-211307, Information on: http://gltrs.grc.nasa.gov/reports/2003/TM-2003-211307.pdf

[3] ESDU Standard, The design of helical and spur involute gears, ESDU 88033

[4] Wear Debris Analysis Handbook, by B.J.Roylance and T.Hunt, Cooxmoor Publishing, 1999 